\title{
EXAMINING THE EFFECTS OF SLEEP DEPRIVATION ON WORKPLACE DEVIANCE: A SELF-REGULATORY PERSPECTIVE
}

\author{
MICHAEL S. CHRISTIAN \\ University of North Carolina at Chapel Hill \\ ALEKSANDER P. J. ELLIS \\ University of Arizona
}

\begin{abstract}
The causes of workplace deviance are of increasing interest to organizations. We integrate psychological and neurocognitive perspectives to examine the effects of sleep deprivation on workplace deviance. Utilizing self-regulatory resource theories, we argue that sleep deprivation decreases individuals' self-control while increasing hostility, resulting in increased workplace deviance. We test our hypotheses using two samples: one comprised of nurses from a large medical center and another comprised of undergraduate students participating in a lab study. Results from both samples largely converge in supporting our hypotheses.
\end{abstract}

Workplace deviance represents "voluntary behavior that violates significant organizational norms, and in so doing, threatens the well-being of the organization and/or its members" (Robinson \& Bennett, 1995: 556). Deviance behaviors range from theft, violence, vandalism, and drug use, to interpersonal rudeness, withholding of effort, and leaving early or arriving late to work (Robinson \& Bennett, 1995). All are problematic for organizations. For example, yearly losses due to theft are estimated at over 40 billion dollars (Coffin, 2003), and the annual cost of absenteeism in the United States is estimated to be around 30 billion dollars (Steers \& Rhodes, 1984). In the aggregate, deviant behavior costs organizations as much as 200 billion dollars annually (Murphy, 1993). Moreover, employees' exposure to other employees' deviance can lead to stress-related problems, low morale, damaged self-

This article was based on the first author's dissertation research, conducted at the University of Arizona. We would first like to thank Stephen Gilliland and Jerel Slaughter for their valuable insights and suggestions as members of the first author's dissertation committee. We would also like to thank our action editor and the anonymous reviewers for their developmental comments throughout the review process, which led to a much stronger manuscript. Additionally, we appreciate the insightful comments of Dick Bootzin, Jessica Siegel, Noah Eisenkraft, and Kevin Hill. Finally, we would like to thank Mel Win Khaw and Courtney Collen for their assistance in data collection.

Editor's note: The manuscript for this article was accepted for publication during the term of $A M J$ 's previous editor, Duane Ireland. esteem, increased fear at work, and turnover (Giacalone, Riordan, \& Rosenfeld, 1997; Griffin, O’Leary-Kelly, \& Collins, 1998; O’Leary-Kelly, Griffin, \& Glew, 1996).

A growing body of research is concerned with identifying precursors of workplace deviance, including various contextual elements such as social influence, job stressors, and organizational justice issues (e.g., Fox, Spector, \& Miles, 2001; Glomb \& Liao, 2003; Greenberg, 1990; Robinson \& O’LearyKelly, 1998). In the current research, we argue that theories of self-regulatory resources (e.g., Baumeister, Heatherton, \& Tice, 1994), or "the internal resources available to inhibit, override, or alter responses that may arise as a result of physiological processes, habit, learning, or the press of the situation" (Schmeichel \& Baumeister, 2004: 86), can help isolate sleep deprivation as a precursor to deviant behavior, which occurs because of impairments in key self-regulatory abilities related to the modulation of behavior and emotions.

Sleep research is becoming more relevant to organizational scholars, as the number of hours worked annually in the United States has increased steadily over the past several decades (National Institute for Occupational Safety and Health [NIOSH], 2004), contributing to a growing culture of sleep deprivation. Rising economic concerns have exacerbated the problem. In 2009, the National Sleep Foundation (NSF) estimated that one third of Americans are losing sleep owing to financial and economic distress. In fact, the number of Americans who sleep fewer than six hours per night increased from 13 to 20 percent between 1999 
and 2009 (NSF, 2009). Some have argued that our society is chronically sleep-deprived, with potentially disastrous consequences (Bonnet \& Arand, 1995; Ferrara \& De Gennaro, 2001). Sleep deprivation is known to have effects on alertness (Thomas et al., 2000), performance of dynamic tracking tasks (Collins, 1977), decision-making capacity (Harrison \& Horne, 2000), occupational injuries (Barnes \& Wagner, 2009), and worker well-being (NIOSH, 2004). Sleep deprivation costs approximately US $\$ 150$ billion annually in terms of accidents and lost productivity for the U.S. economy (National Center on Sleep Disorders Research, 2003). However, we believe that sleep deprivation may also be costly in terms of its effects on deviant behavior.

Therefore, our goal in this study is to use a selfregulatory resource perspective to highlight the potential consequences of sleep deprivation for workplace deviance. In doing so, we argue that two critical states underlie the relationship between sleep deprivation and workplace deviance: selfcontrol and hostility (see Figure 1). We define selfcontrol as a state of mental energy, control, and strength that enables the exertion of control over the self by the self (e.g., Muraven \& Baumeister, 2000; Twenge, Muraven, \& Tice, 2004). We define hostility as a negative emotional state characterized by feelings such as irritability, anger, and disgust (e.g., Watson \& Clark, 1994).

We feel that our study offers a significant contribution to the organizational literature by integrating research from the social psychological, sleep, and neurocognitive literatures to develop and test a theoretically and empirically driven model of the effects of sleep deprivation on workplace deviance. By grounding our model in theories of self-regulatory resources, we identify a primary motivational mechanism of deviant behavior and extend recently surfacing evidence regarding the physiological bases of self-regulation (Gailliot et al., 2007; Masicampo \& Baumeister, 2008). We believe our self-regulatory model can help explain the tendency for sleep-deprived individuals to behave in a deviant manner and can help us pinpoint the mechanisms underlying the effects of sleep deprivation on workplace deviance in an effort to expand the nomological net surrounding both variables and highlight the significant role of selfcontrol and hostility in the process.

The remainder of the article unfolds as follows. First, we discuss workplace deviance, arguing that a self-regulatory resource framework can extend current theoretical models. Second, we discuss the effect of sleep deprivation on deviance. Third, we discuss the mediating role of specific self-regulatory mechanisms (i.e., self-control and state hostility).

\section{Workplace Deviance and Self-Regulation}

Workplace deviance refers to behaviors that are (1) voluntary, (2) violate organizational norms, and (3) threaten the well-being of an organization and/or its members (Bennett \& Robinson, 2000; Robinson \& Bennett, 1995). Deviance behaviors can be classified along two dimensions based on whether the behaviors' target is organizational or interpersonal. Although meta-analyses of research on deviance (Berry, Ones, \& Sackett, 2007) and

FIGURE 1

Conceptual Model

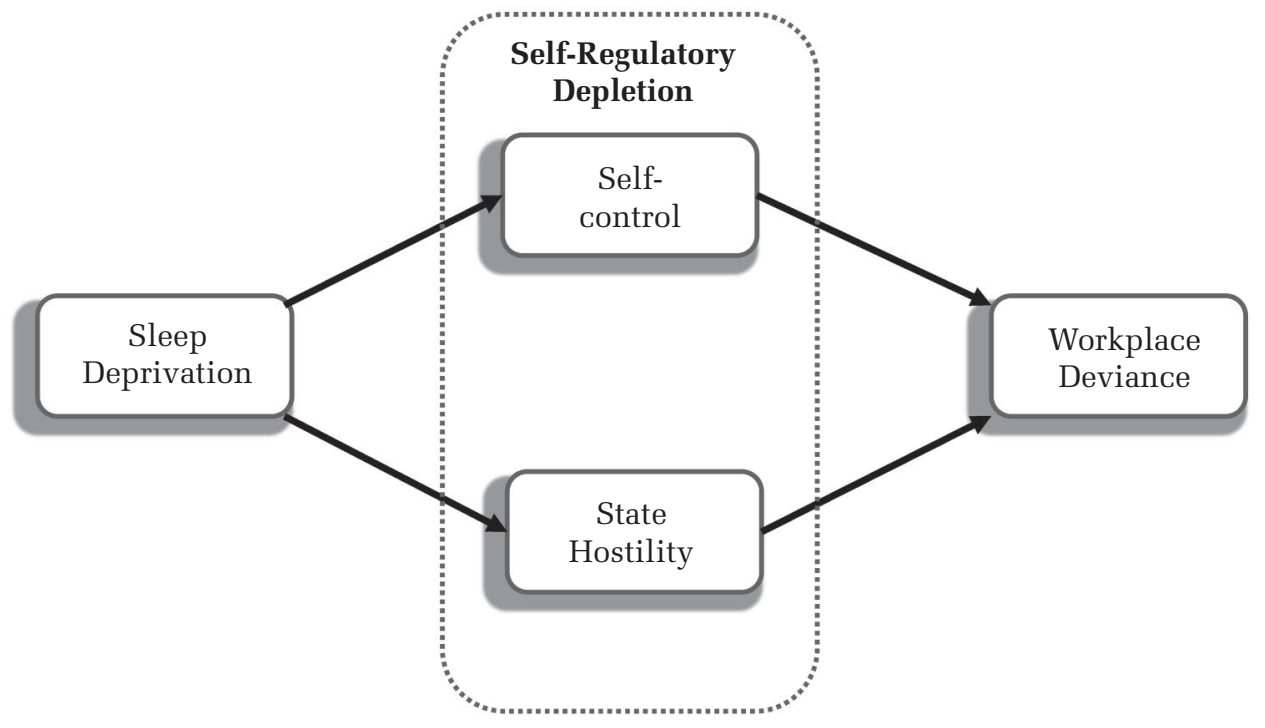


workplace aggression (Hershcovis et al., 2007) have suggested that the target dimensions may be distinct, we argue that, in line with Lee and Allen (2002) and Judge, Scott, and Ilies (2006), it is more appropriate to focus on overall deviance in this study. Antecedents have been shown to similarly affect both organizational and interpersonal deviance (Berry et al., 2007; Hershcovis et al., 2007); the two dimensions are highly related to one another (e.g., $r_{\mathrm{c}}=.86$ [Bennett \& Robinson, 2000]; $r_{\mathrm{C}}=.96$ [Lee \& Allen, 2002]; $\rho=.62$ [Berry et al., 2007]); and our theoretical arguments do not imply different relationships between variables of interest and organizational and interpersonal deviance.

Deviance is volitional (Bennett \& Robinson, 2000) and can be motivated by specific instrumental cognitions such as thoughts of revenge or retaliation (e.g., Bies \& Tripp, 1998; Bordia, Restubog, \& Tang, 2008; Martinko, Gundlach, \& Douglas, 2002), or by a desire for personal gain (Spector \& Fox, 2005). Deviance can also be motivated by the need to vent or express discrete emotions (e.g., Lee \& Allen, 2002), such as anger or frustration (Robinson \& Bennett, 1997).

We believe that a key to understanding the motivational mechanisms of deviance lies in theories of self-regulation. An individual's capacity to selfregulate, or to control or inhibit his/her behaviors and emotions, is likely to impact the extent to which that individual acts in a normatively inappropriate, or deviant, manner. When self-regulatory efforts fail, nonoptimal motivational tendencies exert a greater influence on behavior (Baumeister, Gailliot, DeWall, \& Oaten, 2006; Baumeister \& Vohs, 2007). As a result, volitional behaviors that would otherwise be inhibited are more likely to occur.

Self-regulatory resource models (Baumeister et al., 1994; Muraven \& Baumeister, 2000; Muraven, Tice, \& Baumeister, 1998) suggest that thoughts, behaviors, and emotions are governed by finite and consumable resources that resemble energy ${ }^{1}$ (Baumeister \& Vohs, 2003; Muraven \& Baumeister, 2000). These resources sustain all forms of selfregulation, representing a generalized, or executive, function that allows people to control impulses, desires, and emotions. Individuals have a relatively stable self-regulatory capacity, yet this

\footnotetext{
1 Self-regulatory resource models differ from attentional resource models (Kahneman, 1973; Kanfer, 1990; Kanfer \& Ackerman, 1989) in that they predict a subsequent, rather than a concurrent, reduction in self-regulation (Beal et al., 2005; Schmeichel \& Baumeister, 2004). In this sense, self-regulatory resources resemble energy (Baumeister et al., 1998), rather than merely cognitive capacity.
}

can be depleted as a function of resource availability (DeWall, Baumeister, Stillman, \& Gailliot, 2007; Gailliot et al., 2007). As we argue next, sleep deprivation has the potential to deplete self-regulatory resources, and depletion can lead to deviance.

\section{The Effect of Sleep Deprivation}

Sleep is a homeostatic process that has a restorative effect on the brain and determines individual alertness (Saper, Scammell, \& Lu, 2005; Weinger \& Ancoli-Israel, 2002). Total or partial sleep deprivation represents an induced state of reduced cognitive capacity (Barnes \& Hollenbeck, 2009). Total sleep deprivation is the result of at least one night of no sleep, and partial sleep deprivation is the result of interrupted or shortened sleep. Although optimal sleep quantity depends on many factors, including individual differences in sleep requirements (Van Dongen, Baynard, Maislin, \& Dinges, 2004) and chronic sleep restriction from insomnia or other factors (e.g., "sleep debt" [Ferrara \& De Gennaro, 2001]), the prevailing view in sleep research is that 7 or more hours of sleep in a 24-hour period is sufficient for most people (Ferrara \& De Gennaro, 2001).

Total and partial sleep deprivation are known to have deleterious effects on human functioning. When measures of mood, cognition, and motor functioning are collapsed together, evidence indicates that the mean level of functioning for sleepdeprived individuals is around the ninth percentile of non-sleep-deprived individuals (Pilcher \& Huffcutt, 1996). Although sleep deprivation has been shown to have little effect on logical reasoning and rule-based cognition, its effects on divergent thinking and self-regulation are well documented (Harrison \& Horne, 2000). As evidence, sleep-deprived individuals tend to perform normally on standardized tests (Blagrove, Alexander, \& Horne, 1995; Harrison \& Horne, 1999; Horne, 1988; Percival, Horne, \& Tilley, 1982), but poorly on tasks requiring innovative thinking, risk analysis, and strategic planning (Harrison \& Horne, 1998, 1999; Horne, 1988; McKenna, Dickinson, Orff, \& Drummond, 2007).

Total and partial sleep deprivation also occur across a variety of occupations owing to shift work, high workloads, sleep-related disorders, certain medications, and life style factors such as a new baby (Harrison \& Horne, 2000; Weinger \& AncoliIsrael, 2002). Although partial sleep deprivation is more commonplace, many jobs require extended periods of total sleep deprivation. Examples include the jobs of physicians, who are often on call for 24 continuous hours at least once per week 
(Weinger \& Ancoli-Israel, 2002), military professionals, and executives working internationally and thus forced to adjust to time zone changes. We believe that both total and partial sleep deprivation have implications for the incidence of workplace deviance.

From a neuroscientific perspective, the effects of sleep deprivation on human behavior result from decreased brain functioning, particularly in the prefrontal cortex (Durmer \& Dinges, 2005). This region contains a critical set of neocortical structures that are part of a network of areas in the brain that have "executive" or "supervisory" control (Jennings, Monk, \& Van der Molen, 2003) and have been implicated in the ability to control emotions and inhibit behaviors (Damasio, 1994; Miller, 2000). Sleep-deprived individuals often act impulsively, engage in interpersonally inappropriate behaviors, and do not adhere to social norms (Harrison \& Horne, 2000; Horne, 1993; Reynolds \& Schiffbauer, 2004). These results are consistent with research indicating that impairment to the prefrontal cortex increases antisocial behaviors such as deceit, aggression, and violence (Anderson, Bechara, Damasio, Tranel, \& Damasio, 1999; Grafman, 1996).

Given that sleep deprivation reduces the executive function of the brain, we argue that it depletes self-regulatory resources. Neuroscience suggests that sleep deprivation impairs the prefrontal cortex through reductions in glucose metabolism (Dahl \& Lewin, 2002; Pilcher \& Huffcutt, 1996). Glucose, a fuel for the brain, plays a critical role in the executive function and self-regulation (Gailliot et al., 2007; Masicampo \& Baumeister, 2008). Thus, selfregulatory control of behavior is reduced when the prefrontal cortex region is impaired-a phenomenon otherwise understood as self-regulatory resource depletion.

In sum, our arguments that deviance contains a significant self-regulatory component and that sleep deprivation physiologically impairs the executive function of the brain (i.e., self-regulation) lead to the following:

Hypothesis 1. Sleep deprivation increases the incidence of workplace deviance behaviors.

\section{The Role of Self-Control and State Hostility}

The operation of self-regulatory resources is a broad concept that applies to all forms of self-regulation, including the regulation of behavior and emotions (Muraven \& Baumeister, 2000). We argue that self-regulatory resource depletion leads to deviance through both behavioral (i.e., self-control) and emotional (i.e., state hostility) mechanisms. Below we explain how sleep deprivation can be conceptually and empirically linked to self-control and state hostility, which can then be linked to deviant behavior, establishing both as potential mediators of the relationship between sleep deprivation and deviance.

Self-control. Self-regulatory resources determine an individual's level of self-control, which describes the exertion of control over behavior (Baumeister et al., 1994; Muraven \& Baumeister, 2000). When self-regulatory resources are depleted, self-control is reduced (DeWall et al., 2007; Gailliot, Schmeichel, \& Baumeister, 2006). Given the role of sleep in the executive functioning of the brain, some researchers have speculated that sleep deprivation could impair self-control (Schmeichel \& Baumeister, 2004).

Self-control has also been linked to deviant behavior. Research indicates that individuals who have depleted self-control are less able to suppress or inhibit interpersonally aggressive or potentially destructive impulses (DeWall et al., 2007; Tangney, Baumeister, \& Boone, 2004). Self-control depletion leads individuals to act on impulses, often making risky decisions (Leith \& Baumeister, 1996). Mead, Baumeister, Gino, Schweitzer, and Ariely (2009) found that when participants performed a task requiring the exertion (and thus depletion) of selfcontrol and were given the opportunity to cheat on a subsequent task, they were more likely to succumb to temptation. However, as yet, we only have direct evidence regarding the effects of trait selfcontrol on workplace deviance (Bordia et al., 2008; Douglas \& Martinko, 2001; Marcus \& Schuler, 2004). ${ }^{2}$

In sum, drawing on self-regulatory resource theories, we argue that sleep deprivation decreases selfcontrol and increases the incidence of workplace deviance. Because we also argue that self-control negatively affects workplace deviance, we believe self-control represents one mechanism underlying the relationship between sleep deprivation and workplace deviance, deriving the following:

Hypothesis 2. Self-control partially mediates the relationship between sleep deprivation and workplace deviance.

State hostility. Because the ability to regulate emotions also involves the prefrontal cortex (Davidson, Putnam, \& Larson, 2000; Urry et al., 2006),

\footnotetext{
2 We define trait variables as being relatively stable over time and conceptualized to vary between individuals and state variables as malleable characteristics that are conceptualized to vary within individuals.
} 
sleep deprivation has the potential to impair emotion regulation, whereby individuals modulate the emotions they experience, when they experience them, and how they express them (Gross, 1998). In support of this idea, research has indicated that prefrontal impairment leads to increased negative emotions and poor emotion regulation (Davidson et al., 2000). Although results of laboratory studies have been inconclusive as to whether self-regulatory resource depletion leads directly to negative mood (e.g., Gailliot et al., 2006; Muraven \& Baumeister, 2000), it is clear that depletion does reduce the ability to regulate negative emotions (Finkel \& Campbell, 2001; Gailliot et al., 2006; Muraven et al., 1998). Individuals with low regulatory resources are likely to react to potentially frustrating or difficult situations in their work environments with negative emotions such as hostility, which, we argue, becomes an issue for sleep-deprived employees.

In their review, Durmer and Dinges (2005) concluded that virtually all forms of sleep deprivation result in negative emotions. Their conclusion was based on numerous studies indicating that sleep deprivation affects the experience and expression of irritability, hostility, and anger (e.g., Harrison \& Horne, 2000; Pilcher, Ginter, \& Sadowsky, 1997; Samkoff \& Jacques, 1991; Zohar, Tzischinsky, Epstein, \& Lavie, 2005). For instance, Zohar and colleagues (2005) found that sleep loss influenced the intensity of medical residents' emotional responses to events requiring self-regulation. Because resource depletion undermines emotion regulation, negative emotions experienced following sleep deprivation are more likely to be expressed and experienced (Scott \& Judge, 2006).

Negative emotions have also been shown to be related to workplace deviance (Fox et al., 2001; Judge et al., 2006; Lee \& Allen, 2002; Spector \& Fox, 2002), and "approach-oriented" emotions such as hostility and anger are particularly problematic considering that they are associated with aggressive reactions (Buss \& Perry, 1992; Harmon-Jones \& Sigelman, 2001). From a self-regulatory perspective, when negative emotions are experienced, employees react in two ways. First, they tend to make emotion regulation their short-term priority, because they are motivated to feel better, and so they often fail to achieve self-regulatory goals such as behavioral self-control (Tice \& Bratslavsky, 2000; Tice, Bratslavsky, \& Baumeister, 2001; Vohs \& Heatherton, 2000). Thus, negative emotions can lead individuals to commit impulsive, potentially deviant behaviors if they expect their mood to improve through their doing so. Second, the energy required to control emotions is drawn from the same pool of resources used in the self-regulation of behavior (Beal, Weiss, Barros, \& MacDermid, 2005; Tice et al., 2001; Tice \& Bratslavsky, 2000). If employees expend resources to regulate negative emotions, it becomes more difficult for them to control deviant tendencies and impulses (Marlatt, 1985; Zillmann, 1993).

Given our arguments above, which stem primarily from self-regulatory resource theories, we expect sleep deprivation to increase hostility and the incidence of workplace deviance. Because we also argue that state hostility positively affects workplace deviance, we believe state hostility represents a second mechanism underlying the relationship between sleep deprivation and deviance:

Hypothesis 3. State hostility partially mediates the relationship between sleep deprivation and workplace deviance.

\section{SAMPLE 1: METHODS}

\section{Sample Description}

Sample 1 consisted of 171 nurses from a major medical center in the southwestern United States. Eighty-two percent of the sample members were female, and 75 percent were white. Fortytwo percent were between 21 and 30 years of age (mean $=36$, s.d. $=11.79)$. Fifty-seven percent of the sample's members worked the day shift, from 7:00 a.m. until 7:00 p.m., and 43 percent worked the night shift, from 7:00 p.m. until 7:00 a.m. Eighteen percent reported having children under the age of four at home. Preliminary analyses revealed that working the night shift was not related to sleep deprivation $(r=.07)$ or total hours slept $(r=.15)$; and having a young child was not related to sleep deprivation $(r=.13)$ or total hours slept $(r=.07)$.

\section{Procedures}

Recruitment took place under the supervision of the head of nursing research, who presented an overview of the study to the clinical leaders of each unit. Subsequently, we contacted each clinical leader to arrange a time for a brief presentation of the study. Clinical leaders then informed the nursing staff that the study would be conducted, that they would receive a payment of $\$ 20$ each for completing the surveys, and that, if they wished to participate, they should arrive to work ten minutes earlier than usual on the day of survey administration. The response rate was 90 percent.

During the study, a researcher was present in the morning and in the evening to distribute surveys. Nurses only participated on one day. Participants 
were informed that the study concerned sleep and decision making. Nurses received survey 1 (which contained measures of sleep deprivation, self-control, and hostility) at the beginning of their shift. After a period of 12 hours (or one work shift), the same nurses received survey 2 (containing measures of workplace deviance and control variables). These surveys were linked via a self-issued identification number (issued at the time of taking survey 1) to maximize confidentiality.

Because our sample completed a survey with all self-reported variables, which is typical in deviance research (Berry et al., 2007), we attempted to limit the potential for common method effects by following the recommendations of Podsakoff, MacKenzie, Lee, and Podsakoff (2003), who suggested temporally spacing the predictor and criterion variables. Doing so reduces the salience of the predictor and mediators when the dependent variable is being assessed, thereby reducing recall-related biases and demand effects. We also protected the anonymity of the respondents to reduce evaluation apprehension, which reduces the effects of socially desirable responding (Podsakoff et al., 2003) and the fear of punishment for any admission of deviance (Bennett \& Robinson, 2000). Finally, as recommended by Podsakoff and colleagues (2003), we partialed out the effects of trait affectivity, which is a common source of method bias (Brief, Burke, George, Robinson, \& Webster, 1988).

\section{Measures}

Sleep deprivation. Following previous research, we operationalized partial sleep deprivation categorically (e.g., Barnett \& Cooper, 2008; Chen, Gill, \& Prigerson, 2005; Gangwisch, Malaspina, Boden-Albala, \& Heymsfield, 2005; Kripke, Garfinkel, Wingard, Klauber, \& Marler, 2002). We chose 6 hours as the cutoff point. Consensus has emerged in several reviews of the sleep literature that sleeping 6 or fewer hours leads to cognitive impairment, whereas sleeping 7 or more does not. For example, Ferrara and De Gennaro fixed on a daily sleep quota of 7-8 hours and noted that "a large and robust body of data indicates unequivocally that even a relatively modest sleep curtailment of that average sleep amount leads to impaired levels of alertness and performance" (2001: 174). Similarly, Durmer and Dinges (2005) defined partial sleep deprivation as sleeping fewer than 7 hours in a night. Both Bonnet and Arand (1995) and Weinger and AncoliIsrael (2002) concluded that sleep durations of 5-6 hours can have deleterious consequences on mood, performance, and alertness, a conclusion that other research has consistently supported. A number of studies have shown that people who sleep fewer than 7 hours have higher mortality rates (Kripke et al., 2002), poorer social functioning and emotional health, lower energy, and reduced performance (Bonnet, 2000; Chen et al., 2005). Although a few studies have used more extreme criteria (e.g., 5 hours or less [Pilcher \& Huffcutt, 1996]), we follow the consensus and consider partial sleep deprivation to exist when a person gets 6 or fewer hours of sleep in a 24-hour period. ${ }^{3}$

The measure asked the nurses to indicate the number of whole hours slept the night before the survey. Specifically, the nurses filled in the exact hours during which they were asleep using a series of check-boxes for each hour of the day. If an individual had slept six or fewer hours, she/he received a code of 1, indicating that sleep deprivation. Anyone who had slept seven or more hours received a 0 , indicating no sleep deprivation. No participant reported total sleep deprivation (three hours was the lowest amount reported).

\footnotetext{
${ }^{3}$ We chose not to conceptualize partial sleep deprivation as a continuous variable for three reasons. First, because our interest was in sleep deprivation rather than sleep duration, we felt it was not appropriate to differentiate between individuals who slept an optimal amount and those who slept more. Second, there is no clear evidence that sleep deprivation operates linearly. In their meta-analysis, Pilcher and Huffcutt (1996) found that getting five hours or of sleep or less actually has stronger negative effects than total sleep deprivation-stronger, on average, by more than two standard deviations-on mood and cognitive functioning. Third, extending sleep beyond seven hours is only marginally beneficial to cognitive functioning (Ferrara \& De Gennaro, 2001). The restorative benefits of sleep are thought to follow an asymptotic function that is such that benefits begin to taper off as sleep duration increases (Bonnet \& Arand, 1995). Still, to test the validity of our operationalization of sleep deprivation, we regressed deviance on sleep deprivation as a continuous variable and found no evidence of a linear relationship $(\beta=-.10$, n.s.). We also conducted post hoc analyses to determine whether the six-hour cutoff was appropriate by examining alternative cutoffs at five and seven hours, while including the control variables in the regression model. When we operationalized sleep deprivation as five hours of sleep or less (and no sleep deprivation as six hours or more), sleep deprivation did not have a significant relationship with deviance ( $\beta=.05$, n.s.). When we operationalized sleep deprivation as getting seven hours of sleep or less (and no sleep deprivation as getting eight hours or more), sleep deprivation did not have a significant relationship with deviance $(\beta=.08$, n.s.). These results support use of the six hours cutoff point.
} 
Self-control. Self-control was assessed with the State Self Control Capacity Scale (Twenge et al., 2004). This 25-item scale assesses perceptions of the momentary availability of self-regulatory resources. Participants rated items $(\alpha=.96)$ on a scale ranging from 1, "very slightly or not at all," to 5, "very much." The items are listed in Appendix A. High scores indicated high levels of selfcontrol.

Hostility. State hostility was assessed with the six-item hostility subscale of the Positive and Negative Affect Schedule-Expanded Form (PANAS-X; Watson \& Clark, 1994). Participants were asked to indicate the extent to which they had experienced a particular emotion in the past hour using the same five-point scale described above. Items included "angry," "hostile," "irritable," "scornful," "disgusted," and "loathing" ( $\alpha=.87)$.

Workplace deviance. Workplace deviance was assessed with 17 items from Bennett and Robinson's (2000) measure. We conducted an interview with the supervisor to ensure that each of our items fit the definition of deviance and eliminated 2 items (i.e., "Dragged out work to get overtime" and "Falsified a receipt to get reimbursed for more money than you spent on business expenses"). Participants were asked to indicate "how often they had engaged in the behavior today" (1, "never," to 5, "often"). Sample items include "Discussed confidential information with an unauthorized person," "Used an illegal drug or consumed alcohol on the job," "Worked on a personal matter instead of work for your employer," "Said something hurtful to someone at work," and "Intentionally worked slower than you could have worked" $(\alpha=.86)$.

Control variables. In terms of individual differences, we first controlled for trait positive and negative affect, assessed using the PANAS-X (Watson \& Clark, 1994), because of affect's likely relation with the variables of interest in this study (Lee \& Allen, 2002). Controlling for positive and negative affect also helped us reduce the potential for common method effects (Podsakoff et al., 2003). We then controlled for gender, because research has shown that men are more likely to commit acts of deviance at work than are women (Berry et al., 2007).

We also controlled for several variables related to chronic sleep issues that could have effects on deviance through self-regulatory depletion. Thus, we measured sleep debt, or the number of hours slept on the two nights preceding the survey, and chronic insomnia (i.e., trouble falling asleep and staying asleep). Also we controlled for sleep requirement, assessed as the average number of hours each participant believed that he or she needed in a night to feel rested (Van Dongen et al., 2004). ${ }^{4}$ Finally, we controlled for the number of hours participants had been awake before the first survey (hours awake) to control for the effects of duration of wakefulness, which is associated with fatigue and increased depletion (Baumeister \& Vohs, 2003).

\section{SAMPLE 1: RESULTS}

Table 1 provides the means, standard deviations, and correlations between the Sample 1 variables.

\section{Tests of Hypotheses}

Table 2 shows the results of the hierarchical regression analyses testing our hypotheses. In the first step, we entered the control variables, finding that sleep requirement, negative affect, and gender significantly affected workplace deviance.

Hypothesis 1 proposes that sleep deprivation increases workplace deviance. As shown in Table 2, when we entered sleep deprivation in the second step of our hierarchical regression, it had a significant relationship with workplace deviance that went over and above the relationship due to the effects of the control variables $\left(\beta=.16, \Delta R^{2}=.02\right.$, $p<.05$ ), supporting Hypothesis 1.

Hypotheses 2 and 3 propose that self-control and hostility mediate the effects of sleep deprivation on workplace deviance. We followed the three-step procedure outlined by Baron and Kenny (1986) to test these hypotheses. According to Baron and Kenny, the first requirement for mediation is that the independent variable be significantly related to the dependent variable, a condition that, as noted above, was supported. The second requirement is that the effects of the independent variable on the mediating variables be significant. After entering our control variables in the first step, we found that regression analyses indicated that sleep deprivation significantly affected self-control $(\beta=-.15$, $\left.\Delta R^{2}=.02, p<.05\right)$ and hostility $(\beta=.30$, $\Delta R^{2}=.08, p<.01$ ), allowing us to move on to the final requirement for mediation. To satisfy Baron

\footnotetext{
4 As a reviewer noted, according to our arguments, it is plausible that sleep requirement moderates the effects of sleep deprivation on deviance. Therefore, we entered the interaction between sleep deprivation and sleep requirement as a possible control variable. However, the interaction term was nonsignificant $(\beta=.01, p=.86)$ and did not change any of the parameters of interest. Therefore, we present the results in Table 2 with the interaction term excluded from the model. However, results with the interaction term included are available from the first author upon request.
} 
TABLE 1

Means, Standard Deviations, and Correlations among Sample 1 Variables $^{\mathrm{a}}$

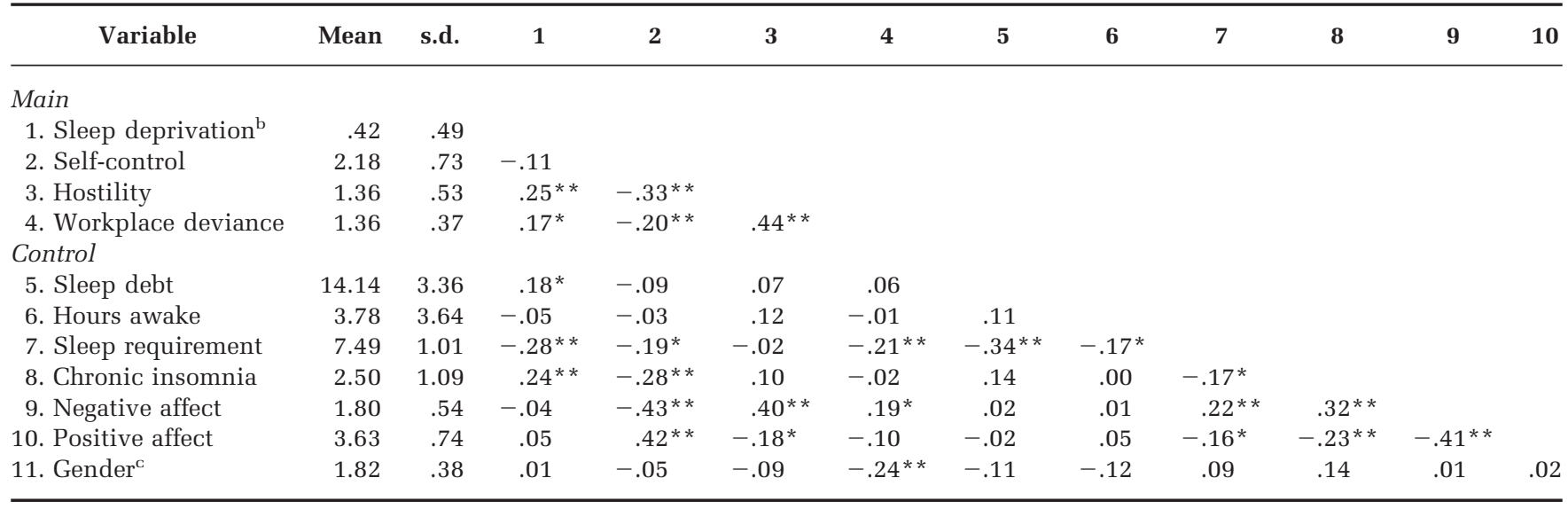

a $n=171$.

b Coded as 0, "more than six hours slept," or 1 "six or fewer hours slept."

c Coded as 1, "male"; 2, "female."

$* p<.05$

** $p<.01$

and Kenny's third requirement, we examined whether the effects of sleep deprivation on workplace deviance were reduced significantly when self-control and hostility were entered simultaneously in the presence of sleep deprivation. As shown in the third step in Table 2, self-control significantly affected workplace deviance $(\beta=-.16, p<.05)$, as did hostility $(\beta=.36$, $p<.01$ ), and the effects of sleep deprivation on

TABLE 2

Mediated Regression Results for Effect of Sleep Deprivation on Workplace Deviance in Sample $1^{\mathrm{a}}$

\begin{tabular}{llll}
\hline \multicolumn{1}{c}{ Variable } & Step 1 & Step 2 & Step 3 \\
\hline Control & & & \\
Sleep debt & -.05 & -.06 & -.07 \\
Hours awake & -.08 & -.06 & -.12 \\
Sleep requirement & $-.31^{* *}$ & $-.28^{* *}$ & $-.30^{* *}$ \\
Chronic insomnia & -.15 & $-.18^{*}$ & $-.16^{*}$ \\
Negative affect & $.28^{* *}$ & $.29^{* *}$ & .10 \\
Positive affect & -.07 & -.07 & -.01 \\
Gender & $-.21^{* *}$ & $-.21^{* *}$ & $-.20^{* *}$ \\
Main & & & .03 \\
Sleep deprivation & & $.16^{*}$ & .03 \\
Mediators & & & $-.16^{*}$ \\
Self-control & & & $.36^{* *}$ \\
Hostility & $.18^{* *}$ & $.20^{* *}$ & $.32^{* *}$ \\
Total $R^{2}$ & $.18^{* *}$ & $.02^{*}$ & $.12^{* *}$ \\
$\Delta R^{2}$ & & & \\
\hline
\end{tabular}

${ }^{\text {a }} n=171$. All coefficients are standardized regression coefficients.

$\begin{array}{rl}* & p<.05 \\ * * \quad p & <.01\end{array}$ workplace deviance became nonsignificant in the presence of the two mediators $(\beta=.03$, n.s.).

To test the significance of the indirect effect of sleep deprivation through self-control and hostility, we used Preacher and Hayes's (2008) approach to examining multiple mediation models in regression. Preacher and Hayes developed this procedure as an extension of the Sobel test (Sobel, 1982) for testing indirect effects in models that include more than one mediator. In such models, a researcher is concerned not only with the significance of the total indirect effect (through both mediators) on the dependent variable, but also with the significance of specific indirect effects. The advantage of this simultaneous approach is that one can test the extent to which each hypothesized mediator mediates the effect of the independent variable on the dependent variable in the presence of other mediators in the model. This reduces the likelihood of parameter bias owing to omitted variables and enables comparing the magnitudes of the indirect effects.

As Preacher and Hayes (2008) and others (e.g., Shrout \& Bolger, 2002; Williams \& MacKinnon, 2008) have recommended, we estimated the indirect effects using unstandardized coefficients from the full model (i.e., the third step in the regression model) and utilized bootstrapping procedures with 1,000 resamples to place $95 \%$ confidence intervals (CIs) around the estimates of the indirect effects. An indirect effect is significant at the .05 level when the 95\% CI does not include zero (Shrout \& Bolger, 2002). Results indicated that the indirect 
effect of sleep deprivation on workplace deviance was significant through self-control (coefficient $=.02,95 \% \mathrm{CI}=.002, .05)$ and hostility (coefficient $=.08,95 \% \mathrm{CI}=.03, .16)$. Finally, the total indirect effect was significant, with a coefficient of .10 , and the $95 \%$ CI did not include zero $(.04, .18)$, providing support for Hypotheses 2 and 3.

\section{SAMPLE 2: METHODS}

\section{Overview}

We collected a second set of data from a laboratory sample for several reasons. First, the design enabled us to manipulate sleep deprivation. Second, this type of design enabled a test of the effects of total sleep deprivation rather than partial sleep deprivation. Third, a lab study allowed for more appropriate causal inference via the use of random assignment and the manipulation of the independent variable. Thus, replication in the lab allowed us to strengthen the internal validity of our model by reducing the possibility of common method effects, the influence of spurious variables, and so on. Fourth, the lab context allowed us to measure many of our variables of interest behaviorally rather than through questionnaires. Fifth, although the base rate for more extreme behaviors (e.g., theft) might have been lower in our field sample, the lab study allowed us to better assess more severe components of workplace deviance.

\section{Sample}

Sample 2 consisted of 75 junior and senior business students at a large university in the southwestern United States. The average age of participants was 21.5 (s.d. $=4.42$ ), and 48 percent were women. Participants were recruited for the study through an online sign-up system in the business college. During the initial recruitment process, potential participants were not informed of the purpose of the study. The online system administered a survey screening potential participants for cigarette use because spending a night without smoking might have had effects on irritability associated with nicotine withdrawal. The screening survey also assessed any physical and psychological problems that might increase risk (e.g., sleep disorders, heart problems, anemia, epilepsy, brain damage, clinically diagnosed psychological disorders). In total, the screening process eliminated 33 participants. Each remaining participant was randomly assigned to one of two experimental conditions and notified of the opportunity to sign up for study times offered for that condition. Participants were also told that the study dealt with sleep and decision making. Thirty-seven participants were placed in the sleep deprivation condition, and 38 were placed in the control group.

All participants received course credit for their participation. Also, all were paid for their performance on one of the tasks (mean $=\$ 8.50$, s.d. $=\$ 1.64)$. Participants in the sleep deprivation condition were paid an additional $\$ 60$, conferred at the end of the study during debriefing. We did not inform participants of the payment schedule for those in the other condition to minimize potential equity issues.

\section{Manipulation}

We adapted our manipulation from Harrison and Horne (1999), using a between-subjects design. Participants in both conditions ("sleep deprivation" [SD] and no sleep deprivation [NSD]) underwent the experiment in groups of six to ten individuals. We conducted the study over the course of two days (day 1 and day 2). Sleep deprivation was manipulated on the night of day 1 , and participants in both groups began the actual experimental procedures at 9:00 a.m. on day 2.

Prior to day 1, the SD group received an e-mail with instructions to prepare for the study by (1) not taking naps on day 1, (2) not bringing their own food or beverages to the lab, (3) not drinking alcohol the night before day 1, (4) getting normal sleep-no less than seven hours-two nights before day 1, (5) waking no later than 9:00 a.m. on day 1 to ensure at least 24 hours of sleep deprivation, and (6) arranging for a friend or family member to pick them up upon completion of the study. The SD participants entered the lab at 10:00 p.m. on day 1 and began the experimental measures and tasks at 9:00 a.m. on day 2, following a full night of sleep deprivation during the night of day 1. During sleep deprivation, participants were confined to a lounge with board games, TV, books, magazines, and snacks available. Two research assistants were paid to monitor participants in shifts to ensure that no participants slept.

Prior to day 1, the control group (NSD) was instructed in an e-mail to (1) get normal sleep-no less than seven hours-for the two nights before day 1 , and also to get normal sleep on the night of day 1, (2) not bring their own food or beverages to the lab, (3) not drink alcohol the night before the study, (4) not eat any food or drink any caffeinated beverage before arriving in the lab on day 2, and (5) not use any stimulants such as nicotine on day 2 . The NSD participants arrived at the lab on the morning of day 2 and began the experimental mea- 
sures and tasks at 9:00 a.m., following a full night of normal sleep during the night of day 1 . We describe the experimental tasks and procedures in more detail below.

\section{Procedures}

Breakfast was served to all participants at 8:30 a.m. on day 2. No caffeine or high-sugar foods were served. At 9:00 a.m., participants completed the self-control task (described below) and a questionnaire assessing their current level of hostility. Participants also completed the manipulation check at this point.

After finishing the survey, participants in both conditions were informed that the next phase of the study involved the completion of two tasks. First, participants drafted e-mail responses to fictitious undergraduate students who were interested in applying to the business college. Second, participants completed an 11-item measure of mathematical reasoning and grammatical ability. Each task, described in more detail below, assessed behaviors associated with workplace deviance, including interpersonally deviant acts such as aggression and rudeness, and organizationally deviant acts such as theft.

\section{Measures}

Self-control. We used the method described by Vohs and colleagues (Vohs, Baumeister, Schmeichel, Twenge, Nelson, \& Tice, 2008; Vohs \& Heatherton, 2000) for behaviorally measuring state self-control. ${ }^{5}$ Participants were taken to individual rooms and asked to perform simple but tedious arithmetic problems for "as long as they felt like." They were instructed that they could stop once they had "quit, finished, or given up" on the problems. This represents a classic measure of self-control (Vohs et al., 2008) because participants were allowed to stop working on the problems at any time, and so the impulse to stop had to be overridden to persist in the task. The more time that participants spent on the problems, the higher their self-control.

Hostility. State hostility was assessed with the hostility subscale of the PANAS-X (Watson \& Clark, 1994). Participants were asked to indicate the ex-

\footnotetext{
5 We also collected data from the lab sample using the State Self Control Capacity Scale (Twenge et al., 2004) to provide convergent validity evidence for the measures of self-control used in each sample (i.e., nurses and students). The correlation between the self-report measure of self-control used in sample 1 and the behavioral measure of self-control used in sample 2 was $.57(p<.01)$.
}

tent to which they had experienced a particular emotion in the past hour on a scale ranging from 1 , "very slightly or not at all," to 5 , "very much." The six items for hostility included "angry," "hostile," "irritable," "scornful," "disgusted," and "loathing" $(\alpha=.82)$.

Interpersonal deviance. Interpersonal deviance was assessed with an e-mail task adapted from Evans and Gilliland (2006). Participants were seated at individual computer stations. The experimenter explained that the business school had developed an electronic mentoring program as a resource for prospective applicants who were current undergraduates at the university, whereby they could contact upper-level business students with questions about the school and its programs. Participants were told that their role as mentor would be to represent the business school by answering questions from potential applicants. Participants were told they would be pilot-testing this resource by accessing a temporary e-mail account that contained two messages from prospective students. They were then instructed to respond to the e-mails however they deemed appropriate. Although participants were made to believe the e-mails were real, all participants responded to the same two fictitious messages:

(a) Dear [Business School] Mentor, I am just curious about the classes they offer. I am planning on paying my own way thorugh $[s i c]$ college and I am wondering if there are any classes that are a waste of my time and money there and if so why? Thanx-Raj

and

(b) Are the [business school's] students stuck up like it seems or are the $[s i c]$ some nice ones? Not to be rude, but I don't really care much about getting in there anyway and so I am not even sure why im [sic] here.-jill

Participants' responses were coded for interpersonal deviance. Following Robinson and Bennett (1995), who classified verbal abuse of customers as interpersonally deviant, we considered an interpersonally inappropriate remark to a potential applicant as deviant because the responder voluntarily violated the implicit norms associated with the mentor role. Further, such a remark had the potential to harm the business school by negatively representing it to potential applicants. The lead researcher and a graduate assistant, both blind to condition, rated participant responses using a coding system based on the Bennett and Robinson (2000) measure. The coders looked for any instances in which the response ridiculed or made fun of the sender or included hurtful statements, statements that contained ethnic, religious, or ra- 
cial remarks, cursing, or rude or embarrassing remarks (e.g., "That is a stupid question"). Both coders were trained to rate interpersonal deviance using a behaviorally anchored rating scale (BARS) ranging from 1 (low deviance) to 5 (high deviance). This scale was based on severity and frequency of the deviant content. For example, a highly deviant response would be rude frequently (e.g., including no salutation or signature, a belittling comment, and a harsh tone), and/or severely (directly making hurtful comments clearly intended to harm the original sender).

The two coders rated 20 of the e-mails together and discussed any potential discrepancies to increase reliability. Each coder then rated a separate set of 20 e-mails individually so that we could calculate interrater reliability. As Cohen's kappa was .82, evidence of interrater reliability was sufficient (see Landis \& Koch, 1977), and the remaining 110 e-mails were divided equally between the two coders. Because the scores on the e-mails were significantly correlated $(r=.48, p<.01)$, we created a composite variable by averaging the scores on the two e-mails for each participant.

Theft. Theft was assessed with Vohs and Schooler's (2008) method. We created two sets (form A and form B) of 11 multiple choice questions. The two forms were designed to be equivalent and contained items resembling those found in the Graduate Record Examination (GRE). We included questions from the quantitative section (e.g., "If a cube has a surface area of 216 , what is its volume?") and the verbal section, where instructions asked participants to identify errors in an underlined portion of a sentence and choose a replacement (e.g., "Scarecrows are strange because they are not really scary, neither are they crows"). We administered one of the forms first, as a pretest to establish a baseline for actual performance, and then administered the second form, to assess theft.

Participants were informed that they had 25 minutes to complete each test and would receive $\$ 1$ for each correct answer. After participants had completed the pretest, the experimenter graded it and paid them. The experimenter then informed the participants that the test was proprietary (owned by Educational Testing Services) but, although it was not appropriate to keep a record of their scores, it was fine to use the test for practice purposes. Participants were informed that they needed to score their own work, pay themselves $\$ 1$ for each correct answer, taking the dollar from an envelope (which contained \$12), and tear up and discard their answers before leaving the room. Once participants had completed the second test, the experimenter returned to the lab to count the money remaining in each envelope and assess how much each participant had taken.

Although sleep-deprived individuals perform normally on IQ tests (Percival et al., 1982), GMAT tests of critical reasoning (Harrison \& Horne, 1999), and reading comprehension (Webb, 1986), we tested our assumption that any differences in the amount of money taken following the second test reflected theft rather than actual performance differences. The two forms were counterbalanced so that for half of the participants, form A was administered as the pretest and form B was administered as the measure of theft, and for the other half, form $\mathrm{B}$ was the pretest and form $\mathrm{A}$ was the measure of theft. As expected, there were no differences between the forms on scores $(F[1,71]=1.20$, n.s.). Also, there were no differences between the SD $($ mean $=8.03)$ and NSD participants (mean $=8.22)$ with regard to actual performance on the pretest $(F[1,71]=0.28$, n.s. $)$.

\section{SAMPLE 2: RESULTS}

Table 3 provides the means, standard deviations, and correlations between the Sample 2 variables.

\section{Manipulation Check}

We checked the effectiveness of our manipulation in two ways. First, all participants in the SD group were monitored throughout the night to ensure that they did not sleep. Second, participants completed a brief questionnaire assessing the number of hours of sleep they had obtained each of the previous three nights. One hundred percent of participants in the sleep deprivation condition reported 0 hours of sleep for the night preceding the study $($ mean $=0.00$, s.d. $=0.00)$, whereas 100 percent of control participants reported at least 7 hours (range $=7-10$ hours, mean $=8.00$, s.d. $=0.75$ ). There were no significant differences between conditions in terms of amount of sleep obtained two $(F[1,73]=0.01$, n.s. $)$ or three nights before $(F[1,73]=0.28$, n.s. $)$.

\section{Tests of Hypotheses}

Table 4 provides the results of the hierarchical regression analyses used to test our hypotheses. Hypothesis 1 proposes that sleep deprivation positively affects workplace deviance. When we entered sleep deprivation in the first step of our hierarchical regression, it significantly affected both theft ( $\beta=.28, p<.05, R^{2}=.08$ ) and interpersonal deviance $\left(\beta=.27, p<.05, R^{2}=.07\right)$, supporting Hypothesis 1 . The analysis of variance (ANOVA) 
TABLE 3

Means, Standard Deviations, and Correlations among Sample 2 Variables $^{\mathrm{a}}$

\begin{tabular}{|c|c|c|c|c|c|c|}
\hline Variable & Mean & s.d. & 1 & 2 & 3 & 4 \\
\hline 1. Sleep deprivation ${ }^{\mathrm{b}}$ & 0.49 & 0.50 & & & & \\
\hline 2. Self-control ${ }^{\mathrm{C}}$ & 328.87 & 198.69 & $-.54 * *$ & & & \\
\hline 4. Theft ${ }^{\mathrm{d}}$ & 8.52 & 1.64 & $.28^{*}$ & $-.39 * *$ & $.41 * *$ & \\
\hline 5. Interpersonal deviance ${ }^{\mathrm{e}}$ & 2.35 & 0.94 & $.27^{*}$ & -.14 & $.32 * *$ & .16 \\
\hline
\end{tabular}

${ }^{\text {a }} n=75$ (38 control, 37 treatment).

b Sleep deprivation was coded 0, "no sleep deprivation," or 1, "total sleep deprivation."

c Time in seconds spent on arithmetic problems.

d Dollar amount taken during GRE task.

e Coded during an e-mail task, from 1, "low deviance," to 5, "high deviance."

$* p<.05$

** $p<.01$

results indicated that the sleep-deprived group took significantly more money (mean $=8.97$ ) than the control group (mean $=8.08 ; F[1,73]=5.95$, $p<.05$, partial $\eta^{2}=.08$ ), and that the sleep-deprived group was more interpersonally deviant $($ mean $=2.61)$ than the control group $($ mean $=2.11$; $F[1,73]=5.71, p<.05$, partial $\left.\eta^{2}=.07\right)$.

Hypotheses 2 and 3 propose that self-control and hostility mediate the effects of sleep deprivation on workplace deviance. We again followed Baron and Kenny's steps for testing mediation. As noted above, sleep deprivation was significantly related to both theft and interpersonal deviance, satisfying the first requirement for mediation. As for the second step, as shown in Table 3, we found that sleep deprivation was significantly related to self-control $(r=-.54, p<.01)$ and hostility $(r=.43, p<.01)$. An ANOVA revealed that the sleep-deprived group spent less time on the math problems (mean $=221.54$ seconds) than the control group (mean $=433.37$ seconds; $F[1,73]=29.52$, $p<.01$, partial $\eta^{2}=.29$ ) and that the sleep-deprived group had higher levels of hostility $($ mean $=1.50)$ than the control group $($ mean $=1.15 ; F[1,73]=16.97$, $p<.01$, partial $\eta^{2}=.19$ ), supporting the second requirement for mediation. Next we tested the mediated regression model for each dependent variable (the second steps in Table 4). Self-control significantly affected theft $(\beta=-.29, p<.05)$, as did hostility $(\beta=.32, p<.01)$, and the effects of sleep deprivation on theft became nonsignificant in the presence of the two mediators $(\beta=-.02$, n.s.). Selfcontrol did not significantly affect interpersonal deviance $(\beta=-.14$, n.s.), but hostility did $(\beta=.32$,

TABLE 4

Mediated Regression Results for Effect of Sleep Deprivation on Workplace Deviance in Sample $2^{\text {a }}$

\begin{tabular}{|c|c|c|c|c|}
\hline Variable & \multicolumn{2}{|c|}{ Theft $^{\text {b }}$} & \multicolumn{2}{|c|}{ Interpersonal Deviance $^{c}$} \\
\hline \multicolumn{5}{|l|}{ Main effect of condition } \\
\hline Sleep deprivation ${ }^{\mathrm{d}}$ & $.28^{*}$ & -.02 & $.27^{*}$ & .16 \\
\hline \multicolumn{5}{|l|}{ Mediators } \\
\hline Self-controle & & $-.29^{*}$ & & n.a. ${ }^{f}$ \\
\hline$\Delta R^{2}$ & & $.16^{* *}$ & & $.05^{*}$ \\
\hline
\end{tabular}

${ }^{\text {a }} n=75$. All coefficients are standardized regression coefficients.

b Dollar amount taken during GRE task.

c Coded during an e-mail task, from a 1, "low deviance," to 5, "high deviance."

d Sleep deprivation was coded 0, "no sleep deprivation," or 1, "total sleep deprivation."

e Time in seconds spent on arithmetic problems.

${ }^{\mathrm{f}}$ Self-control was not entered in this step because it did not significantly affect interpersonal deviance.

$* p<.05$

** $p<.01$ 
$p<.01$ ), and the relationship between sleep deprivation and interpersonal deviance became nonsignificant in the presence of hostility $(\beta=.16$, n.s.).

To test the significance of the indirect effect of sleep deprivation as mediated by self-control and hostility, we again used the Preacher and Hayes (2008) methodology. Results indicated that the indirect effect of sleep deprivation on theft through self-control was significant (coefficient $=.51$, $95 \%$ CI $=0.09,1.01)$, as was the indirect effect through hostility (coefficient $=.45,95 \% \mathrm{CI}=0.11$, 0.89). Finally, the total indirect effect was significant, with a coefficient of .96, and the 95\% CI did not include zero $(0.42,1.62)$. For interpersonal deviance, the indirect effect of sleep deprivation was significant through hostility (coefficient $=.21$, $95 \%$ CI $=.05, .41)$. In sum, Hypothesis 2 was partially supported, and Hypothesis 3 was fully supported.

\section{DISCUSSION}

The purpose of this two-part study was to merge evidence drawn from social and organizational psychology, sleep research, and neuroscience to develop and test a theoretically and empirically driven model of the effects of sleep deprivation on workplace deviance. Results from our field and lab samples largely converged to show that the effects of sleep deprivation can lead to decreased selfcontrol and increased hostility, which increase the likelihood that individuals will engage in workplace deviance.

\section{Theoretical Implications}

Our findings have implications for research on deviance, particularly given the fact that the latter has tended to focus on identifying potential antecedents but ignored the underlying motivational mechanisms. As Bennett and Robinson (2003) noted, research has primarily focused on the effects of (1) experiences at work, (2) personality, and (3) social context. We move this research forward by uncovering a more proximal determinant of deviance and examine the black box wherein distal factors such as sleep deprivation may result in deviant behavior. Our findings suggest that deviance is motivated by failures in self-regulation that can be induced by depletion. Given that self-regulatory energy can be depleted by a wide range of circumstances that evoke self-control (Muraven et al., 1998; Vohs et al., 2008), emotion control (Muraven et al., 1998; Tice et al., 2001), and information processing, reasoning, and logic (Schmeichel, Vohs, \& Baumeister, 2003), our study provides re- searchers with a new lens for investigating the effects of individual and situational factors on deviance. For example, researchers have found that stress and exhaustion lead to increased deviance (Chen \& Spector, 1992; Fox et al., 2001); our results suggest that self-regulatory failures may mediate this effect.

Also, studies have shown than sleep deprivation has negative effects on mood, cognition, and motor function, but our study directly addresses its effects on behavior that runs counter to compliance with norms and standards at work. In doing so, we respond to calls for systematic research on sleep and self-regulation (Schmeichel \& Baumeister, 2004) and contribute to sleep research by introducing the self-regulatory resource depletion model, which explains the tendency, commonly observed in sleep studies, for sleep-deprived individuals to behave in an antisocial manner (Harrison \& Horne, 2000; Horne, 1993; Kahn-Greene, Lipizzi, Conrad, Kamimori, \& Killgore, 2006; Reynolds \& Schiffbauer, 2004).

In addition, by highlighting the process through which sleep deprivation leads to undesirable antisocial behaviors such as deviance at work, we extend recently surfacing evidence regarding the physiological bases of self-regulation (DeWall et al., 2007; Gailliot et al., 2007) and answer calls to develop models integrating evidence from neuroscience with organizational behavior research (Becker \& Cropanzano, 2009) and in particular, with research on antisocial, unethical, and deviant behavior (Reynolds, 2006; Treviño, Weaver, \& Reynolds, 2006). Our arguments illustrate how research based in neuroscience can contribute to the development of theories in organizational research, and we hope that future studies can begin to develop and utilize paradigms that enable the testing of actual brain activity (e.g., fMRI), rather than making inferences based on associations noted in past neuroscientific studies, as we did in the current research.

Given our findings, we believe that the effects of sleep deprivation may have implications in a wide variety of organizational domains. According to the self-regulatory resource perspective, sleep loss reduces employees' ability to regulate emotions effectively, not their ability to engage in logical reasoning and rule-based cognition. As such, our results may have serious consequences for jobs in which emotional displays are critical. For example, customer service employees, who are frequently required to regulate their emotions, may become more annoyed and have more trouble hiding their negative emotions when dealing with an irate customer if they are sleep deprived. 
Given that self-regulation also plays an important role in reducing accidents (Christian, Bradley, Wallace, \& Burke, 2009), sleep deprivation could create significant problems for employees working in organizations in which safety is an issue. Although several studies have linked safety with sleep, the effects of sleep loss on accidents and injuries are typically considered to be caused by problems associated with motor coordination, alertness, and attention (e.g., Barnes \& Wagner, 2009; Horne \& Reyner, 1999; Marcus \& Loughlin, 1996), rather than self-regulation. Our results suggest that employees who are sleep deprived may be less able to restrain impulses to engage in dangerous behaviors that lead to accidents, injuries, and even death.

Finally, our finding that sleep deprivation reduces self-control directly applies to research in criminology and clinical psychology, as lack of self-control has been linked to substance abuse, poor interpersonal relationships, and criminal behavior (Avakame, 1998; Cherek, Moeller, Dougherty, \& Rhoades, 1997; Cochran, Wood, Sellers, Wilkerson, \& Chamlin, 1998; Gibbs, Giever, \& Martin, 1998; Gottfredson \& Hirschi, 1990; Longshore, 1998; Longshore \& Turner, 1998; Tangney et al., 2004). According to our results, sleep deprivation may increase malfeasance and other socially deviant acts, which are clearly related to unethical behavior. Although unethical behavior is not necessarily the same as organizational deviance (the former refers to behavior that violates accepted moral principles, whereas the latter refers to behavior that violates significant organizational norms [Treviño et al., 2006]), when individuals' self-regulatory capacity is depleted, they may be more likely to engage in behavior that society would consider egregious.

\section{Managerial Implications}

A number of suggestions for managers interested in reducing workplace deviance emerge from our results. As Barnes (in press) noted, these include strategies for limiting sleep deprivation itself and/or for mitigating the effects of sleep deprivation. Managers can limit sleep deprivation using preventive tactics such as sleep awareness training (e.g., insomnia reduction strategies, sleep hygiene counseling) or by attempting to design jobs in a way that reduces long hours and stressful conditions (e.g., scheduling, restricting overtime, reducing shift rotation). In fact, some companies are beginning to adopt policies that help workers sleep more though the promotion of workplace napping or advocating the use of self-help books with sleep tips (Brown, 2004). Managers can also potentially draw on recent evidence suggesting that incentives can mitigate the effects of self-regulatory depletion on behavior (e.g., Baumeister \& Vohs, 2007; Muraven \& Slessareva, 2003). Future research might examine whether rewards or other motivational interventions such as goal setting can reduce the effects of sleep deprivation on behavior at work.

However, managers should be aware of the role of organizational culture in creating conditions that result in sleep deprivation. For example, organizations that promote workaholic cultures in which employees are expected to work long hours should expect to see higher levels of deviance. Managers should also be aware of issues involving workplace fairness, as researchers have shown that injustice at work may lead to higher rates of insomnia among employees (Greenberg, 2006). Finally, given that sleep deprivation is likely for employees with parental responsibilities, managers should consider implementing family-friendly policies such as parental leave to create a more sleep-friendly workplace.

Sleep deprivation is unavoidable in some situations, especially for military personnel, health care professionals, and international businesspeople. In such situations, maintaining a sense of "depletion awareness" is crucial for supervisors. By monitoring employees' current levels of functioning, managers can stay aware of potentially high-risk employees and make informed decisions on the timing of potentially negative events at work. For example, employees may be more likely to retaliate for a perceived injustice when they have been sleep deprived or may be less receptive to negative feedback. Managers can also attempt to keep depleted employees out of situations in which they may be tempted to steal or engage in malfeasance. Finally, as Barnes (in press) suggested, restorative techniques such as scheduling frequent breaks or providing caffeine may increase individuals' resilience to the effects of sleep deprivation.

In sum, we suggest that managers can limit deviance in their organizations by taking the following specific actions: (1) introduce sleep awareness programs, (2) design jobs to limit sleep deprivation, (3) attend to organizational culture, attempting to engender norms that include healthy sleep, (4) monitor employee depletion, and (5) take restorationoriented approaches.

\section{Limitations}

We would like to note that, despite the significance of our results in both studies, both have limitations. Regarding the lab study, we recognize that, although we attempted to simulate workplace 
deviance, we need to remain cautious in generalizing the effects we found using a student sample to workplace contexts. To attain a reasonable level of external validity, we took steps to ensure that the student participants (1) were members of the business school in which the study was conducted, (2) were instructed that the e-mail task that they performed was for the benefit of the organization (i.e., helping to recruit new students), and (3) were instructed that the organization was funding the GRE simulation task-our measure of theft. However, sample members were not employees. In an actual organization, total sleep deprivation may have more of an effect on deviance, because there are larger benefits (i.e., more than a few dollars) to be gained; or it may have less of an effect, because there is much larger risk (i.e., more than being chastised by an experimenter). By contrast, in organizational settings, norms for treating customers with respect may be stronger than they were in our e-mail task, wherein participants were told that they were to represent the business school as mentors to prospective applicants. The strength of customer service norms and display rules in an organization could have a significant impact on the strength of the relationship between sleep deprivation and interpersonally deviant behavior.

Another issue with the lab study involves the fact that, during the night, participants may have become bored, irritated, or more cohesive as a group, in addition to becoming sleep deprived. This is a potentially important limitation present in most experimental studies of sleep deprivation, given that sleep-deprived participants are awake while control group members are not (Durmer \& Dinges, 2005). To tease out the effects of environmental circumstances, future studies of sleep deprivation might include manipulation of the valence of participants' experience during the night or of the extent to which participants are allowed to interact.

Because of the nature of our manipulation, in an effort to eliminate physiological differences between conditions, we also required participants in the control group to adhere to slightly more rigid instructions (no nicotine, caffeine, or food before the morning of the study). Although we could have more effectively eliminated this potential problem by having the control group sleep in the lab under supervision, we chose not to. There is a trade-off between control and ensuring quality sleep, and we decided that quality sleep was more important. Sleep research has clearly and consistently shown a "first-night effect" (Agnew, Webb, \& Williams, 2007) in which participants sleeping in a lab environment are unlikely to adapt to their surroundings, which leads to poor sleep quality.
The field study also exhibited a number of limitations. For one thing, sleep deprivation explained relatively little variance in deviant behavior (around 2 percent). It is possible that deviance was underreported in the field study because of social desirability bias, which can occur when self-report measures are used. However, studies on deviance have shown that this bias does not eliminate reporting of deviance when anonymity is assured (Bennett \& Robinson, 2000), as it was in our study. The vast majority of deviance studies rely on self-report assessments (Berry et al., 2007). In fact, one metaanalysis showed that self-report measures of deviance have stronger relationships with some predictors than external measures of deviance, possibly because (1) deviance is difficult to detect and (2) there is considerable evidence that admissions are related to actual behavior (Ones, Viswesvaran, \& Schmidt, 1993). A second possibility is that deviant behavior occurs infrequently, especially when only one work shift is considered. The mean level of deviance we observed (1.36) does indicate a relatively low base rate, a finding that is consistent with past deviance research using similar measures (Aquino, Lewis, \& Bradfield, 2000; Lee \& Allen, 2002). However, given that our sample of nurses worked in a hospital setting with close supervision and strong norms, our results are likely a conservative estimate of effect sizes for other occupations that involve weaker situations, those in which employees have more autonomy and more opportunities to act deviantly, with fewer consequences. For example, city sanitation workers often work night shifts during which they are away from supervision and have complete behavioral autonomy. Any deviant behavior is likely to go unnoticed and unpunished, given that everyone, including customers, is unaware of what they are doing.

Third, it is possible that the low percentage of variance explained in the field sample compared to the lab sample (where variance explained rose to around 7-8 percent) could have been due to methodological differences between the two studies. For example, in our lab sample, we provided a clearer opportunity for deviance than an employee might encounter at work; providing such a clear opportunity is exactly what one should do when trying to answer "can it happen" questions in the lab (see Ilgen, 1986). Or it could be that that total sleep deprivation had stronger effects than partial sleep deprivation; again, maximizing sleep deprivation represents a significant benefit of conducting lab research. Despite these issues, which we cannot discount analytically, we believe that our results remain significant. Deviance is not a behavior that exhibits the same variance as job performance. In 
other words, a little bit of deviance goes a long way. If deviance increases by even the smallest of margins, lawsuits, turnover, or other serious negative outcomes for organizations can be the result.

Finally, the design of our field study does introduce the possibility of common method bias, and we attempted to deal with the issue following the recommendations of Podsakoff and colleagues (2003). We would also like to note that we went beyond their recommendations and tested our theoretical model and hypotheses using a second sample in which we could randomly assign participants to condition and more accurately establish causality. Given that the hypotheses were supported in both samples, the influence of common method bias was likely not significant. However, to more fully address the issue, we performed Harman's single-factor test, which showed multiple factors in both the field study and the lab study, indicating that no substantial amount of common method variance is present.

\section{Directions for Future Research}

In this study, we were not interested in the potential antecedents of sleep deprivation. However, the issue would be interesting to examine in future research. For example, the reason or reasons for an employee's sleep deprivation may influence his or her mood at work. An individual who was up late talking with old friends may carry positive emotions into the workday, but an individual who was up late arguing with her or his spouse may carry negative emotions into the workday. In our lab study, the cause of sleep deprivation likely engendered positive emotions.

We were also interested in examining sleep deprivation, not chronic sleep restriction (for a review, see Banks and Dinges [2007]). Chronic sleep restriction is defined as partial sleep deprivation endured over consecutive nights. Given the likely prevalence of this condition in today's workforce, future studies of sleep restriction are needed to isolate its effects. For example, individual variability in chronic sleep restriction may represent one factor in determining resistance to sleep loss (Van Dongen et al., 2004).

Aside from chronic sleep restriction, a particularly fruitful avenue for future research is deeper investigation of a range of individual differences that may determine susceptibility to sleep deprivation, such as age and trait self-control. The identification of individual characteristics that buffer the effects of sleep deprivation could be useful for managers concerned with selecting employees for positions that include compromised sleep.
Finally, future research should examine whether the self-regulatory mechanisms in our study influence deviance differently depending on the target dimension. More specifically, hostility may be more strongly linked with incivility (i.e., interpersonal deviance), and self-control may have a stronger effect on more deliberate behaviors (i.e., organizational deviance); our data partially support this argument. Although we did not find differences between self-control and hostility in terms of theft in the lab study, hostility was related to interpersonal deviance, but self-control was not. To further test this idea, we went back to the field data and looked at organizational and interpersonal deviance separately. As in the lab study, we observed no differences between self-control and hostility in terms of organizational deviance. However, hostility mediated the effects of sleep deprivation on interpersonal deviance, but self-control did not. ${ }^{6}$ This result suggests that self-control may not play as important a role as hostility when it comes to incivility in the workplace.

\section{Conclusion}

Although sleep deprivation has increased in the workplace, studies regarding the effects of sleep loss have largely been ignored in the organizational literature. We hope that our efforts to merge evidence drawn from social and organizational psychology, sleep research, and neuroscience highlight the potential effects of sleep deprivation on organizationally relevant criteria such as deviance. If current trends continue, sleep research will be become more important to understanding of employee behavior in organizations and a worthwhile avenue for future research in our field.

\section{REFERENCES}

Agnew, H., Jr., Webb, W., \& Williams, R. 2007. The first night effect: An EEG study of sleep. Psychophysiology, 2: 263-266.

Anderson, S. W., Bechara, A., Damasio, H., Tranel, D., \& Damasio, A. R. 1999. Impairment of social and moral behavior related to early damage in human prefrontal cortex. Nature Neuroscience, 2: 1032-1037.

Aquino, K., Lewis, M., \& Bradfield, M. 2000. Justice constructs, negative affectivity, and employee deviance: A proposed model and empirical test. Journal of Organizational Behavior, 20: 1073-1091.

Avakame, E. F. 1998. Intergenerational transmission of

\footnotetext{
${ }^{6}$ Results are available from the first author upon request.
} 
violence, self-control, and conjugal violence: A comparative analysis of physical violence and psychological aggression. Violence and Victims, 13: 301316.

Banks, S., \& Dinges, D. 2007. Behavioral and physiological consequences of sleep restriction. Journal of Clinical Sleep Medicine, 3: 519-528.

Barnes, C. M. 2011. "I'll sleep when I'm dead”: Managing those too busy to sleep. Organizational Dynamics, 40(1): $18-26$.

Barnes, C. M., \& Wagner, D. T. 2009. Changing to daylight saving time cuts into sleep and increases workplace injuries. Journal of Applied Psychology, 94: 13051317.

Barnes, C., \& Hollenbeck, J. 2009. Sleep deprivation and decision-making teams: Burning the midnight oil or playing with fire? Academy of Management Review, 34: 56-66.

Barnett, K. J., \& Cooper, N. J. 2008. The effects of a poor night sleep on mood, cognitive, autonomic and electrophysiological measures. Journal of Integrative Neuroscience, 7: 405-420.

Baron, R. M., \& Kenny, D. A. 1986. The moderator-mediator variable distinction in social psychological research: Conceptual, strategic, and statistical considerations. Journal of Personality and Social Psychology, 51: 1173-1182.

Baumeister, R. F., Bratslavsky, E., Muraven, M., \& Tice, D. M. 1998. Ego depletion: Is the active self a limited resource? Journal of Personality and Social Psychology, 74: 1252-1265.

Baumeister, R. F., Gailliot, M., DeWall, C. N., \& Oaten, M. 2006. Self-regulation and personality: How interventions increase regulatory success, and how depletion moderates the effects of traits on behavior. Journal of Personality, 74: 1773-1801.

Baumeister, R., Heatherton, T., \& Tice, D. 1994. Losing control: How and why people fail at self-regulation. San Diego: Academic.

Baumeister, R., \& Vohs, K. 2003. Self-regulation and the executive function of the self. In M. Leary \& J. Tangney (Eds.), Handbook of self and identity: 197-217. New York: Guilford.

Baumeister, R., \& Vohs, K. 2007. Self-regulation, ego depletion, and motivation. Social and Personality Psychology Compass, 1: 115-128.

Beal, D. J., Weiss, H. M., Barros, E., \& MacDermid, S. M. 2005. An episodic process model of affective influences on performance. Journal of Applied Psychology, 90: 1054-1068.

Becker, W., \& Cropanzano, R. 2009. Organizational neuroscience: The promise and prospects of an emerging discipline. Journal of Organizational Behavior, 30: $1-5$
Bennett, R. J., \& Robinson, S. L. 2000. Development of a measure of workplace deviance. Journal of Applied Psychology, 85: 349-360.

Bennett, R. J., \& Robinson, S. L. 2003. The past, present, and future of workplace deviance research. In J. Greenberg (Ed.), Organizational behavior: The state of the science (2nd ed.): 247-281. Mahwah, NJ: Erlbaum.

Berry, C. M., Ones, D. S., \& Sackett, P. R. 2007. Interpersonal deviance, organizational deviance, and their common correlates: A review and meta-analysis. Journal of Applied Psychology, 92: 410-424.

Bies, R., \& Tripp, T. 1998. Revenge in organizations: The good, the bad, and the ugly. In R. Griffin, A. O'LearyKelly, \& J. Collins (Eds.), Dysfunctional behavior in organizations: Non-violent dysfunctional behavior: 49-68. Stamford, CT: JAI.

Blagrove, M., Alexander, C., \& Horne, J. 1995. The effects of chronic sleep reduction on the performance of cognitive tasks sensitive to sleep deprivation. Applied Cognitive Psychology, 9: 21-40.

Bonnet, M. H., \& Arand, D. L. 1995. We are chronically sleep deprived. Sleep, 18: 908-911.

Bonnet, M. 2000. Sleep deprivation. In M. Kryger, T. Roth, \& W. Dement (Eds.), Principles and practice of sleep medicine (3rd ed.): 53-71. Philadelphia: W. B. Saunders.

Bordia, P., Restubog, S. L. D., \& Tang, R. L. 2008. When employees strike back: Investigating mediating mechanisms between psychological contract breach and workplace deviance. Journal of Applied Psychology, 93: 1104-1117.

Brief, A. P., Burke, M. J., George, J. M., Robinson, B. S., \& Webster, J. 1988. Should negative affectivity remain an unmeasured variable in the study of job stress? Journal of Applied Psychology, 73: 193-198.

Brown, M. 2004. Taking care of business: Self-help and sleep medicine in American corporate culture. Journal of Medical Humanities, 25: 173-187.

Buss, A. H., \& Perry, M. 1992. The aggression questionnaire. Journal of Personality and Social Psychology, 63: 452-459.

Chen, J. H., Gill, T. M., \& Prigerson, H. G. 2005. Health behaviors associated with better quality of life for older bereaved persons. Journal of Palliative Medicine, 8: 96-106.

Chen, P., \& Spector, P. 1992. Relationships of work stressors with aggression, withdrawal, theft and substance use: An exploratory study. Journal of Occupational and Organizational Psychology, 65: 177184.

Cherek, D. R., Moeller, F. G., Dougherty, D. M., \& Rhoades, H. 1997. Studies of violent and nonviolent male parolees: II. Laboratory and psychometric mea- 
surements of impulsivity. Biological Psychiatry, 41: $523-529$.

Christian, M. S., Bradley, J. C., Wallace, J. C., \& Burke, M. J. 2009. Workplace safety: A meta-analysis of the roles of person and situation factors. Journal of Applied Psychology, 94: 1103-1127.

Cochran, J., Wood, P., Sellers, C., Wilkerson, W., \& Chamlin, M. 1998. Academic dishonesty and low selfcontrol: An empirical test of general theory of crime. Deviant Behavior, 19: 227-256.

Coffin, B. 2003. Breaking the silence on white collar crime. Risk Management, 50: 8.

Collins, W. E. 1977. Some effects of sleep deprivation on tracking performance in static and dynamic environments. Journal of Applied Psychology, 62: 567-573.

Dahl, R. E., \& Lewin, D. S. 2002. Pathways to adolescent health sleep regulation and behavior. Journal of Adolescent Health, 31: 175-184.

Damasio, A. 1994. Descartes' error: Emotion, rationality and the human brain. New York: Putnam.

Davidson, R. J., Putnam, K. M., \& Larson, C. L. 2000. Dysfunction in the neural circuitry of emotion regulation-A possible prelude to violence. Science, 289: 591-594.

DeWall, C., Baumeister, R., Stillman, T., \& Gailliot, M. 2007. Violence restrained: Effects of self-regulatory capacity and its depletion on aggressive behavior. Journal of Experimental Social Psychology, 43: 6276.

Douglas, S. C., \& Martinko, M. J. 2001. Exploring the role of individual differences in the prediction of workplace aggression. Journal of Applied Psychology, 86: 547-559.

Durmer, J. S., \& Dinges, D. F. 2005. Neurocognitive consequences of sleep deprivation. Seminars in Neurology, 25: 117-129.

Evans, J. M., \& Gilliland, S. W. 2006. Unfair customer treatment and managerial trust: Employee reactions to unfair customer policy and treatment. $\mathrm{Pa}$ per presented at the annual meeting of the Academy of Management, Atlanta.

Ferrara, M., \& De Gennaro, L. 2001. How much sleep do we need? Sleep Medicine Reviews, 5: 155-179.

Finkel, E. J., \& Campbell, W. K. 2001. Self-control and accommodation in close relationships: An interdependence analysis. Journal of Personality and Social Psychology, 81: 263-277.

Fox, S., Spector, P., \& Miles, D. 2001. Counterproductive work behavior (CWB) in response to job stressors and organizational justice: Some mediator and moderator tests for autonomy and emotions. Journal of Vocational Behavior, 59: 291-309.
Gailliot, M. T., Baumeister, R. F., DeWall, C. N., Maner, J. K., Plant, E. A., Tice, D. M., Brewer, L. E., \& Schmeichel, B. J. 2007. Self-control relies on glucose as a limited energy source: Willpower is more than a metaphor. Journal of Personality and Social Psychology, 92: 325-336.

Gailliot, M. T., Schmeichel, B. J., \& Baumeister, R. F. 2006. Self-regulatory processes defend against the threat of death: Effects of self-control depletion and trait self-control on thoughts and fears of dying. Journal of Personality and Social Psychology, 91: 49-62.

Gangwisch, J. E., Malaspina, D., Boden-Albala, B., \& Heymsfield, S. B. 2005. Inadequate sleep as a risk factor for obesity: Analyses of the NHANES I. Sleep, 28: 1289-1296.

Giacalone, R., Riordan, C., \& Rosenfeld, P. 1997. Employee sabotage: Toward a practitioner-scholar understanding. In R. Giacalone \& J. Greenberg (Eds.), Antisocial behavior in organizations: 109-129. Thousand Oaks, CA: Sage.

Gibbs, J., Giever, D., \& Martin, J. 1998. Parental management and self-control: An empirical test of Gottfredson and Hirschi's general theory. Journal of Research in Crime and Delinquency, 35: 40-70.

Glomb, T., \& Liao, H. 2003. Interpersonal aggression in work groups: Social influence, reciprocal, and individual effects. Academy of Management Journal, 46: $486-496$.

Gottfredson, M., \& Hirschi, T. 1990. A general theory of crime. Stanford, CA: Stanford University Press.

Grafman, J., Schwab, K., Warden, D. 1996. Frontal lobe injuries, violence, and aggression: A report of the Vietnam Head Injury Study. Neurology, 46: 12311238.

Greenberg, J. 1990. Employee theft as a reaction to underpayment inequity: The hidden cost of pay cuts. Journal of Applied Psychology, 75: 561-568.

Greenberg, J. 2006. Losing sleep over organizational injustice: Attenuating insomniac reactions to underpayment inequity with supervisory training in interactional justice. Journal of Applied Psychology, 91: 58-69.

Griffin, R., O’Leary-Kelly, A., \& Collins, J. 1998. Dysfunctional work behaviors in organizations. In C. L. Cooper \& D. M. Rousseau (Eds.), Trends in organizational behavior, vol. 5: 65-82. Chichester, U.K.: Wiley.

Gross, J. J. 1998. Antecedent- and response-focused emotion regulation: Divergent consequences for experience, expression, and physiology. Journal of Personality and Social Psychology, 74: 224-237.

Harmon-Jones, E., \& Sigelman, J. 2001. State anger and prefrontal brain activity: Evidence that insult-related 
relative left-prefrontal activation is associated with experienced anger and aggression. Journal of Personality and Social Psychology, 80: 797-803.

Harrison, Y., \& Horne, J. A. 1999. One night of sleep loss impairs innovative thinking and flexible decision making. Organizational Behavior and Human Decision Processes, 78: 128-145.

Harrison, Y., \& Horne, J. A. 2000. The impact of sleep deprivation on decision making: A review. Journal of Experimental Psychology: Applied, 6: 236-249.

Harrison, Y., \& Horne, J. 1998. Sleep loss affects risktaking. Journal of Sleep Research, 7(Suppl. 2): 113.

Hershcovis, M. S., Turner, N., Barling, J., Arnold, K. A., Dupré, K. E., Inness, M., LeBlanc, M. M., \& Sivanathan, N. 2007. Predicting workplace aggression: A meta-analysis. Journal of Applied Psychology, 92: $228-238$.

Horne, J. A. 1988. Sleep loss and "divergent" thinking ability. Sleep, 11: 528-536.

Horne, J. 1993. Human sleep, sleep loss and behaviour. Implications for the prefrontal cortex and psychiatric disorder. British Journal of Psychiatry: The Journal of Mental Science, 162: 413-419.

Horne, J., \& Reyner, L. 1999. Vehicle accidents related to sleep: A review. Occupational and Environmental Medicine, 56: 289-294.

Ilgen, D. 1986. Laboratory research, a question of when, not if. In E. Locke (Ed.), Generalizing from lab to field settings: 257-267. Lexington, MA: Heath.

Jennings, J., Monk, T., \& Van der Molen, M. 2003. Sleep deprivation influences some but not all processes of supervisory attention. Psychology Science, 14: 473479.

Judge, T. A., Scott, B. A., \& Ilies, R. 2006. Hostility, job attitudes, and workplace deviance: Test of a multilevel model. Journal of Applied Psychology, 91: 126-138.

Kahneman, D. 1973. Attention and effort. Englewood Cliffs, NJ: Prentice Hall.

Kahn-Greene, E., Lipizzi, E., Conrad, A., Kamimori, G., \& Killgore, W. 2006. Sleep deprivation adversely affects interpersonal responses to frustration. Personality and Individual Differences, 41: 1433-1443.

Kanfer, R. 1990. Motivation and individual differences in learning: An integration of developmental, differential and cognitive perspectives. Learning and Individual Differences, 2: 221-239.

Kanfer, R., \& Ackerman, P. 1989. Motivation and cognitive abilities: An integrative/aptitude-treatment interaction approach to skill acquisition. Journal of Applied Psychology, 74: 657-690.

Kripke, D. F., Garfinkel, L., Wingard, D. L., Klauber,
M. R., \& Marler, M. R. 2002. Mortality associated with sleep duration and insomnia. Archives of General Psychiatry, 59: 131-136.

Landis, J. R., \& Koch, G. G. 1977. The measurement of observer agreement for categorical data. Biometrics, 33: $159-174$.

Lee, K., \& Allen, N. J. 2002. Organizational citizenship behavior and workplace deviance: The role of affect and cognitions. Journal of Applied Psychology, 87: 131-142.

Leith, K. P., \& Baumeister, R. F. 1996. Why do bad moods increase self-defeating behavior? Emotion, risk taking, and self-regulation. Journal of Personality and Social Psychology, 71: 1250-1267.

Longshore, D. 1998. Self-control and criminal opportunity: A prospective test of the general theory of crime. Social Problems, 45: 102-113.

Longshore, D., \& Turner, S. 1998. Self-control and criminal opportunity: Cross-sectional test of the general theory of crime. Criminal Justice and Behavior, 25: 81-99.

Marcus, B., \& Schuler, H. 2004. Antecedents of counterproductive behavior at work: A general perspective. Journal of Applied Psychology, 89: 647-660.

Marcus, C. L., \& Loughlin, G. M. 1996. Effect of sleep deprivation on driving safety in housestaff. Sleep, 19: 763-766.

Marlatt, G. 1985. Relapse prevention: Theoretical rationale and overview of the model. In G. Marlatt \& J. Gordon (Eds.), Relapse prevention: 3-70. New York: Guilford.

Martinko, M., Gundlach, M., \& Douglas, S. 2002. Toward an integrative theory of counterproductive workplace behavior: A causal reasoning perspective. International Journal of Selection and Assessment, 10: $36-50$.

Masicampo, E., \& Baumeister, R. 2008. Toward a physiology of dual-process reasoning and judgment: Lemonade, willpower, and expensive rule-based analysis. Psychology Science, 19: 255-260.

McKenna, B. S., Dickinson, D. L., Orff, H. J., \& Drummond, S. P. 2007. The effects of one night of sleep deprivation on known-risk and ambiguous-risk decisions. Journal of Sleep Research, 16: 245-252.

Mead, N. L., Baumeister, R. F., Gino, F., Schweitzer, M. E., \& Ariely, D. 2009. Too tired to tell the truth: Self control, resource depletion, and dishonesty. Journal of Experimental Social Psychology, 45: 594597.

Miller, E. K. 2000. The prefrontal cortex and cognitive control. Nature Reviews. Neuroscience, 1: 59-65.

Muraven, M., \& Baumeister, R. F. 2000. Self-regulation and depletion of limited resources: Does self-control 
resemble a muscle? Psychological Bulletin, 126: 247-259.

Muraven, M., \& Slessareva, E. 2003. Mechanisms of selfcontrol failure: Motivation and limited resources. Personality and Social Psychology Bulletin, 29: 894-906.

Muraven, M., Tice, D. M., \& Baumeister, R. F. 1998. Self-control as limited resource: Regulatory depletion patterns. Journal of Personality and Social Psychology, 74: 774-789.

Murphy, K. 1993. Honesty in the workplace. Belmont, CA: Brooks/Cole.

National Institute for Occupational Safety and Health. 2004. Overtime and extended work shifts: Recent findings on illnesses, injuries, and health behaviors. Publication 2004-143. Cincinnati: National Institute for Occupational Safety and Health.

National Center on Sleep Disorders Research. 2003. National sleep disorders research plan. Washington, DC: U.S. Department of Health and Human Services.

National Sleep Foundation. 2009. Sleep in America poll. Washington DC: National Sleep Foundation.

O’Leary-Kelly, A., Griffin, R., \& Glew, D. 1996. Organization-motivated aggression: A research framework. Academy of Management Review, 21: 225-253.

Ones, D., Viswesvaran, C., \& Schmidt, F. 1993. Comprehensive meta-analysis of integrity test validities: Findings and implications for personnel selection and theories of job performance. Journal of Applied Psychology, 78: 679-703.

Percival, J., Horne, J., \& Tilley, A. 1982. Effects of sleep deprivation on tests of higher cerebral functioning. Sleep, 6: 390-391.

Pilcher, J. J., Ginter, D. R., \& Sadowsky, B. 1997. Sleep quality versus sleep quantity: Relationships between sleep and measures of health, well-being and sleepiness in college students. Journal of Psychosomatic Research, 42: 583-596.

Pilcher, J. J., \& Huffcutt, A. I. 1996. Effects of sleep deprivation on performance: A meta-analysis. Sleep, 19: 318-326.

Podsakoff, P. M., MacKenzie, S. B., Lee, J. Y., \& Podsakoff, N. P. 2003. Common method biases in behavioral research: A critical review of the literature and recommended remedies. Journal of Applied Psychology, 88: 879-903.

Preacher, K. J., \& Hayes, A. F. 2008. Asymptotic and resampling strategies for assessing and comparing indirect effects in multiple mediator models. Behavior Research Methods, 40: 879-891.

Reynolds, B., \& Schiffbauer, R. 2004. Measuring state changes in human delay discounting: An experien- tial discounting task. Behavioural Processes, 67: 343-356.

Reynolds, S. J. 2006. A neurocognitive model of the ethical decision-making process: Implications for study and practice. Journal of Applied Psychology, 91: 737-748.

Robinson, S., \& Bennett, R. 1995. A typology of deviant workplace behaviors: A multidimensional scaling study. Academy of Management Journal, 38: 555572 .

Robinson, S., \& Bennett, R. 1997. Workplace deviance: Its definition, its manifestations, and its causes. In R. Lewicki, B. Sheppard, \& R. Bies (Eds.), Research on negotiation in organizations, vol. 7: 3-27. Greenwich, CT: JAI.

Robinson, S., \& O’Leary-Kelly, A. 1998. Monkey see, monkey do: The influence of work groups on the antisocial behavior of employees. Academy of Management Journal, 41: 658-672.

Samkoff, J. S., \& Jacques, C. H. 1991. A review of studies concerning effects of sleep deprivation and fatigue on residents' performance. Academic Medicine, 66: 687-693.

Saper, C. B., Scammell, T. E., \& Lu, J. 2005. Hypothalamic regulation of sleep and circadian rhythms. Nature, 437: 1257-1263.

Schmeichel, B. J., Vohs, K. D., \& Baumeister, R. F. 2003. Intellectual performance and ego depletion: Role of the self in logical reasoning and other information processing. Journal of Personality and Social Psychology, 85: 33-46.

Schmeichel, B., \& Baumeister, R. 2004. Self-regulatory strength. In R. Baumeister \& K. Vohs (Eds.), Handbook of self-regulation: Research, theory, and applications: 84-98. New York: Guilford.

Scott, B., \& Judge, T. 2006. Insomnia, emotions, and job satisfaction: A multilevel study. Journal of Management, 32: 622-645.

Shrout, P. E., \& Bolger, N. 2002. Mediation in experimental and nonexperimental studies: New procedures and recommendations. Psychological Methods, 7: $422-445$.

Sobel, M. 1982. Asymptotic confidence intervals for indirect effects in structural equation models. In S. Leinhart (Ed.), Sociological methodology 1982, vol. 13: 290-312. San Francisco: Jossey-Bass.

Spector, P., \& Fox, S. 2002. An emotion-centered model of voluntary work behavior: Some parallels between counterproductive work behavior and organizational citizenship behavior. Human Resource Management Review, 12: 269-292.

Spector, P., \& Fox, S. 2005. The stressor-emotion model of counterproductive work behavior. In S. Fox \& P. Spector (Eds.), Counterproductive work behavior: 
Investigations of actors and targets: 151-174. Washington, DC: American Psychological Association.

Steers, R., \& Rhodes, S. 1984. Knowledge and speculation about absenteeism. In P. Goodman \& R. Atkin (Eds.), Absenteeism, vol. 1: 229-275. San Francisco: Jossey-Bass.

Tangney, J. P., Baumeister, R. F., \& Boone, A. L. 2004. High self-control predicts good adjustment, less pathology, better grades, and interpersonal success. Journal of Personality, 72: 271-324.

Thomas, M., Sing, H., Belenky, G., Holcomb, H., Mayberg, H., Dannals, R., Wagner, H., Thorne, D., Popp, K., \& Rowland, L. 2000. Neural basis of alertness and cognitive performance impairments during sleepiness: Effects of $24 \mathrm{~h}$ of sleep deprivation on waking human regional brain activity. Journal of Sleep Research, 9: 335-352.

Tice, D. M., Bratslavsky, E., \& Baumeister, R. F. 2001. Emotional distress regulation takes precedence over impulse control: If you feel bad, do it! Journal of Personality and Social Psychology, 80: 53-67.

Tice, D., \& Bratslavsky, E. 2000. Giving in to feel good: The place of emotion regulation in the context of general self-control. Psychological Inquiry, 11: 149-159.

Treviño, L., Weaver, G., \& Reynolds, S. 2006. Behavioral ethics in organizations: A review. Journal of Management, 32: 951-990.

Twenge, J., Muraven, M., \& Tice, D. 2004. Measuring state self-control: Reliability, validity, and correlations with physical and psychological stress. Unpublished manuscript, San Diego State University.

Urry, H. L., van Reekum, C. M., Johnstone, T., Kalin, N. H., Thurow, M. E., Schaefer, H. S., Jackson, C. A., Frye, C. J., Greischar, L. L., \& Alexander, A. L. 2006. Amygdala and ventromedial prefrontal cortex are inversely coupled during regulation of negative affect and predict the diurnal pattern of cortisol secretion among older adults. Journal of Neuroscience, 26: 4415-4425.

Van Dongen, H. P., Baynard, M. D., Maislin, G., \& Dinges, D. F. 2004. Systematic interindividual differences in neurobehavioral impairment from sleep loss: Evidence of trait-like differential vulnerability. Sleep, 27: 423-433.

Vohs, K. D., Baumeister, R. F., Schmeichel, B. J., Twenge, J. M., Nelson, N. M., \& Tice, D. M. 2008. Making choices impairs subsequent self-control: A limitedresource account of decision making, self-regulation, and active initiative. Journal of Personality and Social Psychology, 94: 883-898.

Vohs, K., \& Heatherton, T. 2000. Self-regulatory failure: A resource-depletion approach. Psychology Science, 11: $249-254$.
Vohs, K., \& Schooler, J. 2008. The value of believing in free will: Encouraging a belief in determinism increases cheating. Psychology Science, 19: 49-54.

Watson, D., \& Clark, L. 1994. The PANAS-X: Manual for the positive and negative affect schedule-expanded form. Unpublished manuscript, University of Iowa.

Webb, W. B. 1986. Sleep deprivation and reading comprehension. Biological Psychology, 22: 169-172.

Weinger, M., \& Ancoli-Israel, S. 2002. Sleep deprivation and clinical performance. Journal of the American Medical Association, 287: 955-957.

Williams, J., \& MacKinnon, D. P. 2008. Resampling and distribution of the product methods for testing indirect effects in complex models. Structural Equation Modeling, 15: 23-51.

Zillmann, D. 1993. Mental control of angry aggression. In D. Wegner \& J. Pennebaker (Eds.), Handbook of mental control, vol. 5: 370-392. Englewood Cliffs, NJ: Prentice Hall.

Zohar, D., Tzischinsky, O., Epstein, R., \& Lavie, P. 2005. The effects of sleep loss on medical residents' emotional reactions to work events: A cognitive-energy model. Sleep, 28: 47-54.

\section{APPENDIX A State Self-Control Capacity Scale ${ }^{a}$}

1. I feel mentally exhausted.

2. Right now, it would take a lot of effort for me to concentrate on something.

3. I need something pleasant to make me feel better.

4. I feel motivated.

5. If I were given a difficult task right now, I would give up easily.

6. I feel drained.

7. I have lots of energy.

8. I feel worn out.

9. If I were tempted by something right now, it would be difficult to resist.

10. I would want to quit any difficult task I was given.

11. I feel calm and rational.

12. I can't absorb any information.

13. I feel lazy.

14. Right now I would find it difficult to plan ahead.

15. I feel sharp and focused.

16. I want to give up.

17. This would be a good time for me to make an important decision.

18. I feel like my willpower is gone.

19. My mind feels unfocused right now.

20. I feel ready to concentrate.

21. My mental energy is running low.

22. A new challenge would appeal to me right now.

23. I wish I could just relax for a while.

24. I am having a hard time controlling my urges.

25. I feel discouraged.

a This scale from Twenge et al. (2004); $\alpha=.96$. 
Michael S. Christian (mike_christian@unc.edu) is an assistant professor of organizational behavior at the KenanFlagler Business School at the University of North Carolina at Chapel Hill. He completed his Ph.D. in management at the University of Arizona. Dr. Christian's current research is focused on self-control in the workplace as well as on the motivational drivers of deviant and unethical behavior.

\begin{abstract}
Aleksander P. J. Ellis (ellis@eller.arizona.edu) is an associate professor of management at the Eller College of Management, University of Arizona. He earned his Ph.D. in industrial and organizational psychology from Michigan State University. His research interests primarily involve issues related to the behavior of groups and teams in organizations, such as the impact of stress on information-processing capabilities and the role of emergent cognitions in ethical decision making.
\end{abstract}


Copyright of Academy of Management Journal is the property of Academy of Management and its content may not be copied or emailed to multiple sites or posted to a listserv without the copyright holder's express written permission. However, users may print, download, or email articles for individual use. 